OPEN ACCESS

Edited by:

Greeshma Gadikota,

Cornell University, United States

Reviewed by: Iskander Tilit,

Majmaah University, Saudi Arabia

Weihua Cai,

Northeast Electric Power University,

China

Mohammad Alhuyi Nazari,

MAPNA Group, Iran

Siamak Hoseinzadeh,

Sapienza University of Rome, Italy

*Correspondence:

Xiaoxue Luo

Ixx138916@163.com

Specialty section: This article was submitted to Sustainable Energy Systems and

Policies,

a section of the journal

Frontiers in Energy Research

Received: 20 October 2021

Accepted: 31 January 2022

Published: 18 February 2022

Citation:

Lu X, Luo X, Cao S and Zou C (2022)

Experimental Analysis of Heat Storage and Release of Binary Methanol Aqueous Solution Pulsating Heat Pipe

Phase Change Accumulator. Front. Energy Res. 10:798522. doi: 10.3389/fenrg.2022.798522

\section{Experimental Analysis of Heat Storage and Release of Binary Methanol Aqueous Solution Pulsating Heat Pipe Phase Change Accumulator}

\author{
Xiaohui Lu, Xiaoxue Luo*, Shibo Cao and Changzhen Zou \\ School of Mechanical and Marine Engineering, Beibu Gulf University, Qinzhou, China
}

To improve the problems of energy shortage and low utilization rate, this paper designed a set of pulsating heat pipe (PHP) devices coupled with phase change energy storage material. Further, the binary methanol-water solution is proposed as a novel experimental filling medium to enhance the heat transfer performance of the device. The fluid flow model of the PHP was analyzed via experiment and simulation. Besides, the heat storage and release performances of the PHP at different flow rates, different heating temperatures, different filling mediums, and different filling ratios are investigated. The results show that when the filling medium (binary methanol-water solution) possesses the filling ratio of 0.6 (methanol and water are each 0.3), the heat source inlet flow is $0.60 \mathrm{~m}^{3} / \mathrm{h}$, the heat source heating temperature is $120^{\circ} \mathrm{C}$, and the $\mathrm{PHP}$ is at the best heat storage performance. During the exothermic process, the lower the initial temperature of cooling water, the higher the heat recovery rate. Thus, it can be concluded that the selection of an appropriate filling medium and the optimal parameters to enhance heat transfer can have a broader application prospect in the field of waste heat recovery.

Keywords: pulsating heat pipe, phase-change material, methanol-water, heat storage and release performance, enhance heat transfer

\section{INTRODUCTION}

At present, the main problems of energy in China are low energy resources per capita, a large gap between supply and demand, high energy consumption intensity, low efficiency, complex structure, and serious environmental pollution (Wei, 2016; Dong et al., 2017; Wei et al., 2020). The expectation of sustainable development of energy and environment (Gołaś et al., 2019; Mikulcic et al., 2020; Wan and $\mathrm{Ni}, 2020$ ) has attracted widespread attention, with more researches in the fields of solar energy and wind energy (Bilal et al., 2021; Kumar, 2021; Škvorc and Kozmar, 2021). In the field of energy storage, such as the recovery and utilization of ship waste heat, there is a great demand for efficient heat transfer devices, which is a hot research topic at present.

After the oil crisis in the late 1970s, the use of phase-change material (PCM, Phase-change material) for latent heat storage has become an efficient and practical heat storage technology with the large latent heat capacity and near constant temperature, which has a very broad application prospect (Shiina, 2006; Hoseinzadeh et al., 2018; Konuklu, 2018; Murthy et al., 2021). Sheng et al. investigated the thermal performance of barium hydroxide octahydrate PCMs, and the cycle stability and corrosion after 150 thermal cycle tests. The results showed that the phase transition temperature 
of barium hydroxide octahydrate was $78^{\circ} \mathrm{C}$, and it had good compatibility with red copper (Sheng et al., 2013; Sheng et al., 2014).

Pulsating Heat Pipe (PHP) was first proposed by Japanese scholar Akachi in the 1990s, which was regarded as a new type of efficient heat transfer element (Akachi, 1993.). Compared with the traditional heat pipe, PHP is a new type of heat transfer element that can be applied in a small space and has a high heat flux density (Khandekar et al., 2003; Luo et al., 2017). In order to enhance the heat transfer performance of PHP, scholars have carried out research in different directions on the filling medium of PHP, the numerical analysis of heat transfer and simulation.

As research has progressed, some scholars have investigated the type of filling medium in the PHP. In the work of Nazari et al., graphene oxide nanofluids was used as the working medium. And the thermal performance under different concentrations and the flow state of the working fluid under different working conditions were analyzed. The results showed that the use of graphene oxide can reduce the thermal resistance of PHP by $42 \%$. Besides, the low viscosity and high thermal conductivity properties of graphene oxide can improve the thermal performance of PHP(Alhuyi et al., 2018; Nazari et al., 2018). Czajkowski et al. studied the flow state of acetone, ethanol and water as working fluids, and the results showed that acetone had the lowest thermal resistance, and a faster startup speed during the pulsation process (Czajkowski et al., 2020). Chen et al. investigated the effect of the heat transfer performance of PHP when ethane was the filling medium under different heating powers. The results showed that with the increase of heating power, the heat transfer temperature difference would gradually increase (Chen et al., 2019).

As research techniques have advanced, scholars have found that a single filling medium possessed fixed physical parameters, which cannot fully exert all the favorable characteristics of PHP. For example, the heat transfer characteristics of the mixed filling medium are different from the single filling medium, which is due to the different physical parameters, such as the differences in the boiling points and surface tensions of the components. Therefore, the multi-component filling medium can further improve the heat transfer characteristics of PHP. Cui et al. added a small amount of water, methanol, and acetone into ethanol, and investigated the working performance of PHP with the different filling medium. The results showed that the thermal resistance of the ethanol-acetone mixed filling medium was smaller than that of pure ethanol and pure acetone at $45 \%$ filling rate (Cui et al., 2014). B Markal et al. prepared a binary-component filling medium by mixing ethanol and pentane with different ratios. The results showed that the binary mixture had a significant effect on thermal performance, where increasing the content of pentane in the mixture could improve the thermal performance of the heat pipe. (Markal and Varol,2020). Qiao et al. researched the heat transfer performance of PHP when the filling medium was pure methanol, pure acetone, and methanol-acetone mixed filling medium. By comparing the results at different filling rate and heating power, it was concluded that the mixed filling medium can effectively improve the burning dryness of PHP. What' more, the heat transfer performance is relatively good (Tieliang et al.,
2014). Zhu et al. investigated the hot-start performance of PHP with water-acetone mixture as filling medium under different ratios, and the acetone-water binary filling medium had a better hot-start performance compared to the pure filling medium. (Zhu et al., 2014). To sum up, choosing binary solution as the filling medium can reduce energy consumption and save costs.

In terms of numerical analysis of heat transfer, some scholars also have done related research. Tlili et al. used similar variables to convert nonlinear partial differential equations into ordinary differential equations for numerical studies and showed that the variation of viscosity was important. Besides, the study of heat and mass transport was crucial to solving current industrial and scientific problems (Tlili et al., 2021). Ramadan et al. applied numerical methods to investigate the effect of heat transfer on fluid flow and heat transfer in low-speed gas flow in microchannels. And it was showed that the effect of heat transfer on heat exchange between gas and channel wall increased with the decrease of the Knudsen number (Kamil, 2021). Khan et al. evaluated the thermal performance using the well-known Buongiorno model and showed a periodic oscillation near the flow domain through the change of the wall shear stress (Khan et al., 2021). The numerical approach to heat transfer was investigated to better understand the theory associated with heat transfer.

In terms of simulation, Hoseinzadeh et al. used Ansys software to simulate the counter-flow heat exchange system, and analyzed the pressure, temperature, and equivalent thermal stress. In addition, the problem of fluid flow on the horizontal plane on Maxwell was studied, the velocity and temperature profiles were obtained by Maple software, and the heat transfer system and heat transfer performance were well analyzed (Hoseinzadeh and Stephan Heyns, 2020; Hoseinzadeh et al., 2021).

In this paper, based on the above research, a novel design concept was adopted to couple PCM with PHP to further strengthen the heat transfer performance of PHP. Additionally, a binary methanol-water solution was proposed as the experimental filling medium. In the experiment setup, barium hydroxide octahydrate was selected as PCM, $\mathrm{T}_{2}$ copper was used as the shell material of PHP, and the binary methanol-water solution was used as the filling medium. The comparison experiments of heat storage and release experiments under different flow rates, different temperatures and different charging rates was carried out, and the optimal conditions for enhancing heat transfer under binary filling medium were selected according to the comparison of experimental data.

\section{EXPERIMENTAL SETUP}

\section{Brief Introduction of PHP Accumulator}

As demonstrated in Figure 1, a PHP accumulator coupled with PCM has been designed. Copper is selected as the shell material of the PHP with the thickness of $1 \mathrm{~mm}$, the diameter of $4 \mathrm{~mm}$. The device is rectangular, with a length of $218 \mathrm{~mm}$, a width of $128 \mathrm{~mm}$, and a height of $228 \mathrm{~mm}$. From the bottom to the top, the PHP accumulator can be divided into three modules: 


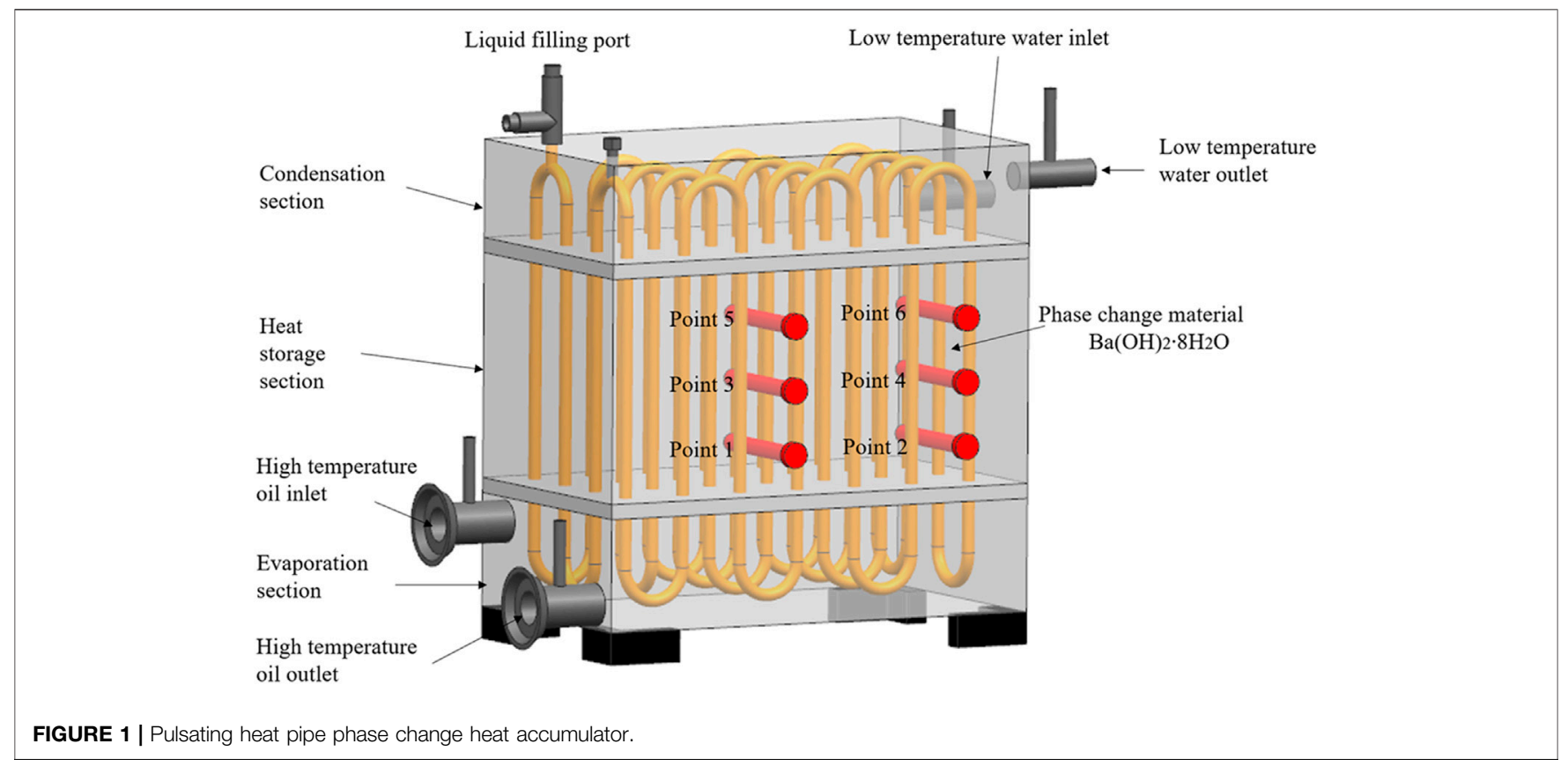

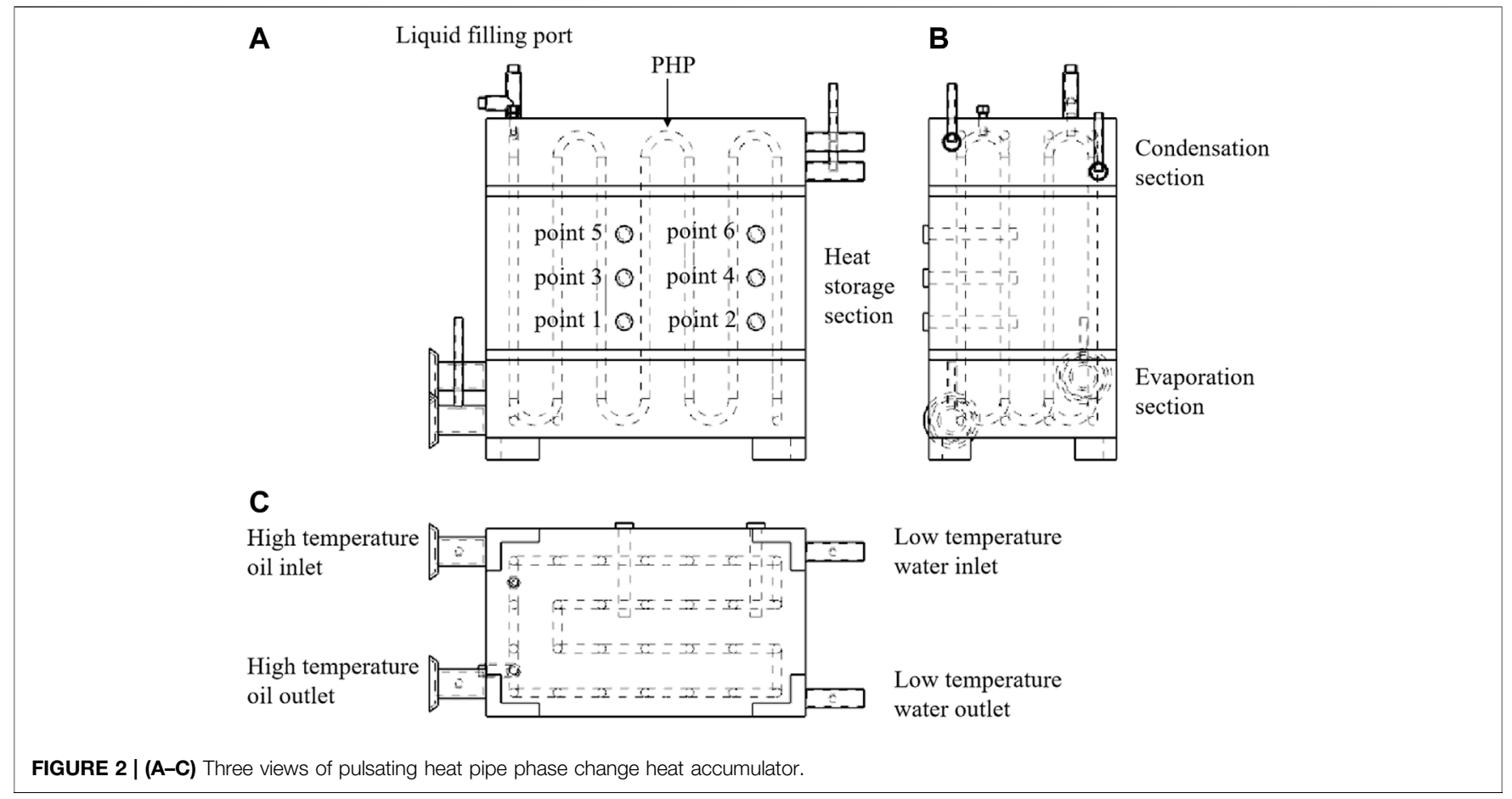

the heating section, the heat storage section, and the condensation section, which are separated by stainless steel plates in the middle. The heating section uses high-temperature silicon oil for constant temperature heating, the heat storage section uses phase change material barium hydroxide octahydrate for heat storage, and the condensation section uses distilled water for cooling. Blind holes and temperature measuring points are arranged in the heat storage section. Among them, there are six measuring points in three rows and two columns on the thermal storage chamber. The bottom layer is where measuring point 1 and 2 are closer to the bottom heating, which can be completely covered by PCM. Afterwards, the measuring points 3 and 4 are located in the middle of the box. Besides, measuring points 5 and 6 are located at the upper position, which are just missed by the PCM. A T-type thermocouple with the accuracy of $\pm 0.5^{\circ} \mathrm{C}$ is inserted for temperature testing, which is convenient for data collection. 

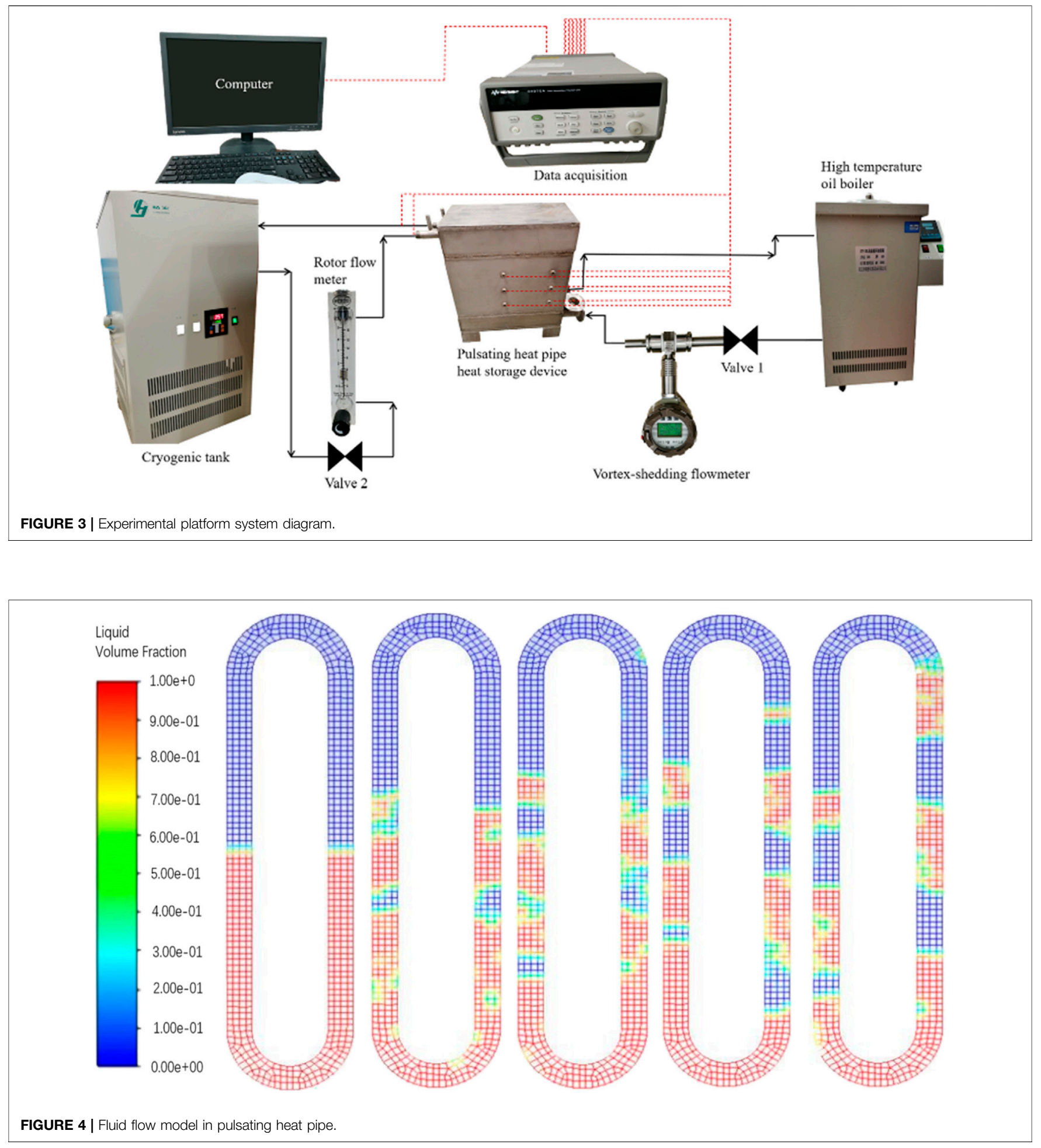

Finally, the heat storage effect of PCM under different working conditions are anlyzed.

The heat transfer in the proposed device relies mainly on the phase change and position change of the filling medium in the PHP. The length of the designed PHP heating section is $45 \mathrm{~mm}$, the length of the heat storage section is $120 \mathrm{~mm}$, and the length of the condensation section is $45 \mathrm{~mm}$. There are totally 28 elbows with the diameter of $30 \mathrm{~mm}$, and 14 elbows in each of the heating section and the radiating section. In order to clearly understand the structure of the PHP, threeview diagram are drawn as shown in Figure 2 as follows. 

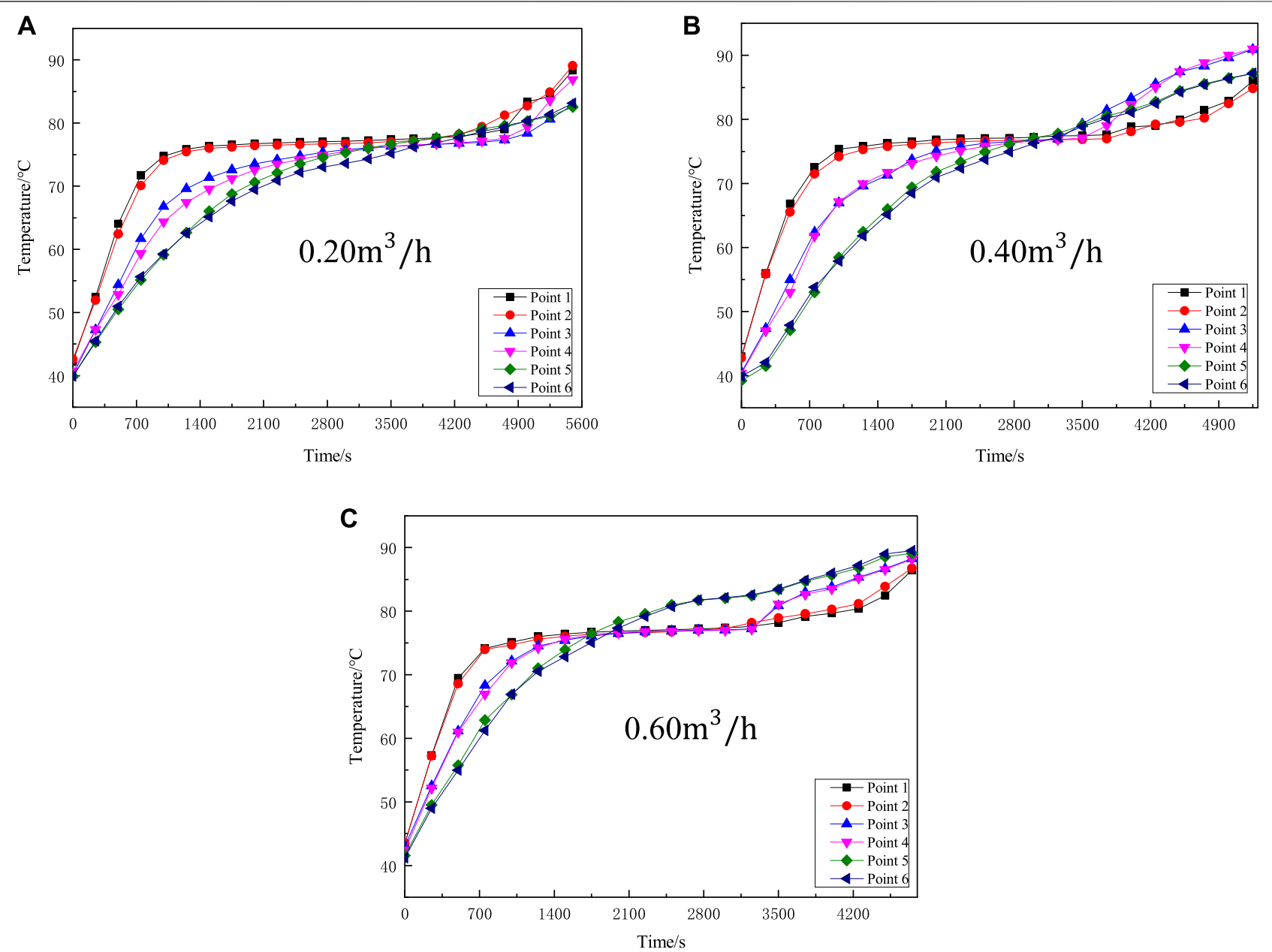

FIGURE 5 | Flow chart of different inlets (A) Flow rate of $0.20 \mathrm{~m}^{3} / \mathrm{h}$ (B) Flow rate of $0.40 \mathrm{~m}^{3} / \mathrm{h}$ (C) Flow rate of $0.60 \mathrm{~m}^{3} / \mathrm{h}$.

\section{Experimental Platform Construction}

The system diagram of the experimental platform for the PHP accumulator is shown in Figure 3.

Experimental method: when the temperature of the PCM in the heat accumulator is heated above the phase-change temperature to change from solid to liquid, close the hightemperature constant-temperature oil bath and open the lowtemperature thermostat bath. The low-temperature thermostat bath is equivalent to a water tank that can set the initial water temperature, accurate quality, and possess better heat insulation performance. The built-in water pump causes the cooling water to circulate back and forth between the low-temperature thermostat bath, thereby leading the PCM in the heat storage radiator solidified to heat the cooling water in the heated water tank. By analyzing the duration of heat storage and release under different working conditions and the temperature rise after the cooling water is heated, the total heat release time, phase change latent heat release time and heat recovery rate of the PHP accumulator are evaluated, so as to find the best setting parameters to achieve the effect of enhanced heat transfer.
Main experimental equipment: Agilent data acquisition instrument, $34970 \mathrm{~A}, \pm 0.1^{\circ} \mathrm{C}$, Agilent Technologies, Inc.; Differential Scanning Calorimeter (DSC), 200F3, $\pm 0.1^{\circ} \mathrm{C}$, Germany Netzsch GmbH; High temperature constant temperature oil bath, GYY-30L, temperature control range is $0-300{ }^{\circ} \mathrm{C}, \pm 0.1^{\circ} \mathrm{C}$, Gongyi Ruide Instrument Equipment Co., Ltd.; Cryogenic tank, DKB-2215, temperature control range is $-20-99^{\circ} \mathrm{C}, \pm 0.1^{\circ} \mathrm{C}$, Shanghai Jinghong Experimental Equipment Co., Ltd.; Vortex flowmeter, BPMLWGY-10BLWSNN, measuring range $0.2-1.2 \mathrm{~m}^{3} / \mathrm{h}, 1 \%$, Beijing Kunlun Yuanhang Measurement and Control Technology Co., Ltd.; T-type thermocouple, $\pm 0.5^{\circ} \mathrm{C}$.

\section{EXPERIMENTAL RESULTS AND DISCUSSIONS}

\section{Model Analysis of Fluid Flow in Pulsating Heat Pipes}

The VOF model is used for solving in Fluent software, and the boundary condition of the evaporation section of the PHP is set to 

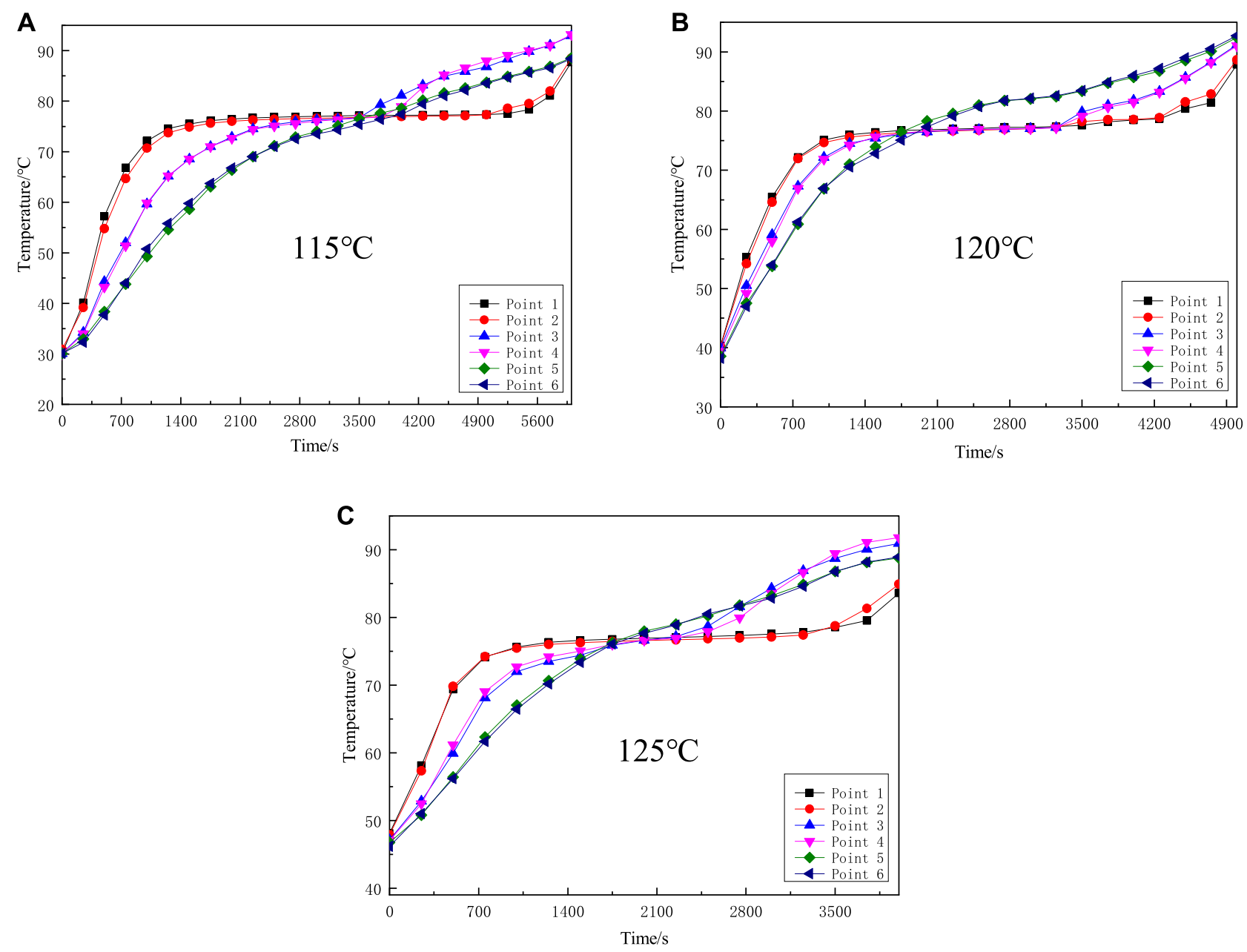

FIGURE 6 | Different heating temperature change graph (A) The heating temperature of $115^{\circ} \mathrm{C}$ (B) The heating temperature of $120^{\circ} \mathrm{C}$ (C) The heating temperature of $125^{\circ} \mathrm{C}$.

the constant temperature of $120^{\circ} \mathrm{C}$ and the wall thickness of $1 \mathrm{~mm}$, the temperature boundary condition of the heat storage section is set to $20^{\circ} \mathrm{C}$, and the wall thickness is $1 \mathrm{~mm}$. The fluid in the tube is defined as three phases: water, water vapor, and air. The surface tension between the phases is set to $0.072 \mathrm{~N} / \mathrm{m}$, and the tube is set as vacuum state. Finally, the calculation is performed after sub-regional initialization. The motion model of the fluid in a PHP from the start of heating to a constant temperature in the pipe is obtained, as shown in Figure 4 below:

The movement trend of the fluid model in PHP after modeling is shown in Figure 4, there is no input of external work such as heat in the initial stage, thus the gas-liquid two-phase distribution in the pipe is relatively uniform. However, the liquid is located below the heat pipe due to the distribution of gravity. At the beginning of the heat storage section, as the heating temperature increases, the inner wall of the heat pipe in this section will attach to the liquid to generate a vaporization core. After the liquid absorbs heat, it vaporizes to form small bubbles and gradually floats upward. The bubbles expand rapidly, and the internal pressure also rises, thereby promoting the small bubbles moving to the gas-liquid interface. Eventually, the bubbles burst due to insufficient surface tension to maintain the shape of the small bubbles. After continuous heating, the vaporization range of the liquid gradually expands, and the small bubbles also grow into gas plugs, eventually forming a state of gas-liquid plugs. Part of the liquid absorbs heat and vaporizes in the heat storage section to form a gas lock and moves to the condensation section under the action of gravity and tension. It is precisely because of the imbalance that the fluid in the tube forms an oscillating effect without the input of external work, which further increases the heat transfer. Therefore, the PHP is also called an oscillating heat pipe. This oscillating effect makes the PHP have a strong heat transfer ability and the ability to level the temperature, so that this PHP is widely used in practical waste heat recovery devices.

\section{Experimental Analysis of Heat Storage at Different Flow Rates}

The experimental conditions are set as the mass of phase-change energy storage material barium hydroxide octahydrate is $4.5 \mathrm{~kg}$, 
the heating temperature is $120^{\circ} \mathrm{C}$, and the inlet flow rate of the heat source is changed to $0.20 \mathrm{~m}^{3} / \mathrm{h}, 0.40 \mathrm{~m}^{3} / \mathrm{h}, 0.60 \mathrm{~m}^{3} / \mathrm{h}$, respectively. The results are as shown in Figure 5 below:

It can be seen from Figure 5 that when the heating fluid flow rate is $0.20 \mathrm{~m}^{3} / \mathrm{h}$ (as shown in Figure 5A), after the PCM reaches the phase transition point, the phase transition time is longer $3,550 \mathrm{~s}$, and the temperature change curves of the six measuring points in the latent heat stage are basically the same was $78^{\circ} \mathrm{C}$. After that, the PCM changes from the latent heat stage to the liquid sensible heat stage, and the temperature rise of measuring points 3 and 4 and measuring points 5 and 6 gradually increase. The reason is that when the flow of the heat source heating fluid is small, the heat provided cannot make the PCM quickly complete the phase change and enter the liquid sensible heat stage. From Figures 5B,C, it can be clearly seen that with the gradual increase of the heat source flow rate, the phase change heat storage time is significantly reduced, and the latent heat duration is reduced from 2,800 s (at $0.40 \mathrm{~m}^{3} / \mathrm{h}$ ) and $2,400 \mathrm{~s}$ (at $0.60 \mathrm{~m}^{3} / \mathrm{h}$ ). Additionally, the total heat storage time is also shortened accordingly. Experiments show that changing the inlet flow rate of the heat source has a significant impact on the heat storage device. Therefore, the optimal flow rate of the phase change heat storage device is $0.60 \mathrm{~m}^{3} / \mathrm{h}$. But the flow cannot be too large, otherwise it will not only increase the cost, but also is not easy to manage.

Thereby, the heat storage process of the phase change heat accumulator can be roughly divided into three parts: the initial solid sensible heat stage, the latent heat storage stage, and the liquid sensible heat stage. The total heat storage time represents the time spent in the three stages. The heat storage of the three stages can be calculated as follows:

$$
\mathbf{Q}_{1}=\mathbf{c}_{\mathbf{s}} \mathbf{m} \Delta \mathrm{T}_{\mathbf{s}}, \mathbf{Q}_{2}=\mathbf{m} \times \mathbf{L P C M}, \mathbf{Q}_{3}=\mathrm{c}_{\mathbf{l}} \mathbf{m} \Delta \mathrm{T}_{1}
$$

Where, $Q_{1}$ is the heat storage of solid sensible heat stage, $Q_{2}$ is the heat storage of latent heat stage, and $Q_{3}$ is the heat storage of liquid sensible heat stage. Among them, the solid specific heat capacity of PCM is approximately $1.17 \mathrm{~kJ} /(\mathrm{kg} \cdot \mathrm{K})$; the liquid specific heat capacity of PCM is $1.77 \mathrm{~kJ} /(\mathrm{kg} \cdot \mathrm{K})$; the quality of the added PCM is $4.5 \mathrm{~kg}$; and the latent heat of phase change LPCM is $285 \mathrm{~kJ} / \mathrm{kg}$. Through calculation, $Q_{1}$ is $200.07 \mathrm{~kJ}, Q_{2}$ is $1282.50 \mathrm{~kJ}$, and $Q_{3}$ is $95.58 \mathrm{~kJ}$. The heat demand in the latent heat stage is about $80 \%$ above. Therefore, the advantage of latent heat storage is very obvious.

\section{Experimental Analysis of Heat Storage at Different Temperatures}

Change the heating temperature of the heat source to $115^{\circ} \mathrm{C}$, $120^{\circ} \mathrm{C}, 125^{\circ} \mathrm{C}$, and observe the temperature changes at each measuring point of the PCM, as shown in Figure 6:

From Figure 6, it can be seen that as the heating temperature of the heat source increases, the latent heat storage and the total heat storage time are gradually shortening, and the latent heat storage time is reduced from $3,800 \mathrm{~s}$ (at $115^{\circ} \mathrm{C}$ ) to $2,200 \mathrm{~s}$ (at $125^{\circ} \mathrm{C}$ ). Therefore, the heating temperature of the heat source has a greater influence on the heat transfer performance of the phase change heat storage device. The higher the heat source temperature, the shorter the phase change heat storage time.

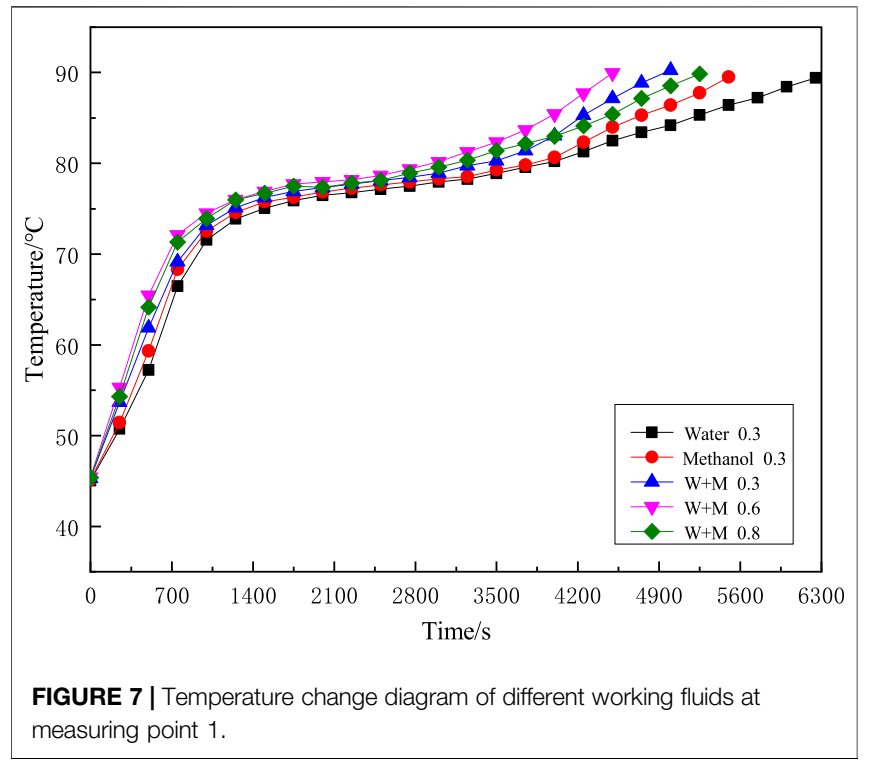

Due to the increase of the heating temperature, the density difference of the liquid PCM during the heat storage melting process is also increased, which strengthens the natural convection phenomenon and improves the effective heat transfer coefficient during the heat storage process. When the effective heat transfer area is not changed, the heat flow density is expanded, which can speed up the storage of heat energy and reduce the time consumption of heat storage at the same time. At the beginning of heating, the higher the heat source temperature, the faster the PCM temperature rises, and the shorter the heat storage time. This is because when the heating temperature of the heat source is different, the heat flux $q$ of the heating area per unit time is different. The higher the heating temperature, the greater the $q$, which is determined by $Q_{\text {latent }}=q \cdot A \cdot \mathrm{t}\left(Q_{\text {latent }}\right.$ is the latent heat). When $Q_{\text {latent }}$ and $A$ are constant, $q$ is inversely proportional to $t$. The results show that appropriately increasing the heating temperature of the heat source can shorten the heat storage time and improve the efficiency. Therefore, $120{ }^{\circ} \mathrm{C}$ is recommended to be the heating temperature, thus the provided safety is guaranteed.

\section{Experimental Analysis of Heat Storage With Different Charging Fluids}

Through the comparative experiments of methanol, water and binary methanol-water solution as the filling medium under different charging rate conditions, the temperature change of PCM at measuring point 1 with time is observed, as shown in Figure 7 below:

It can be seen from Figure 7 that the total heat storage time of methanol-water solution as the binary filling medium is obviously shorter than that of methanol and water. Comparing the filling ratio of $0.3,0.6$ and 0.8 for the binary filling medium fluid methanol aqueous solution, the shortest total heat storage time is achieved at the filling ratio of 0.6. Therefore, it can known that the best effect could be obtained 
A

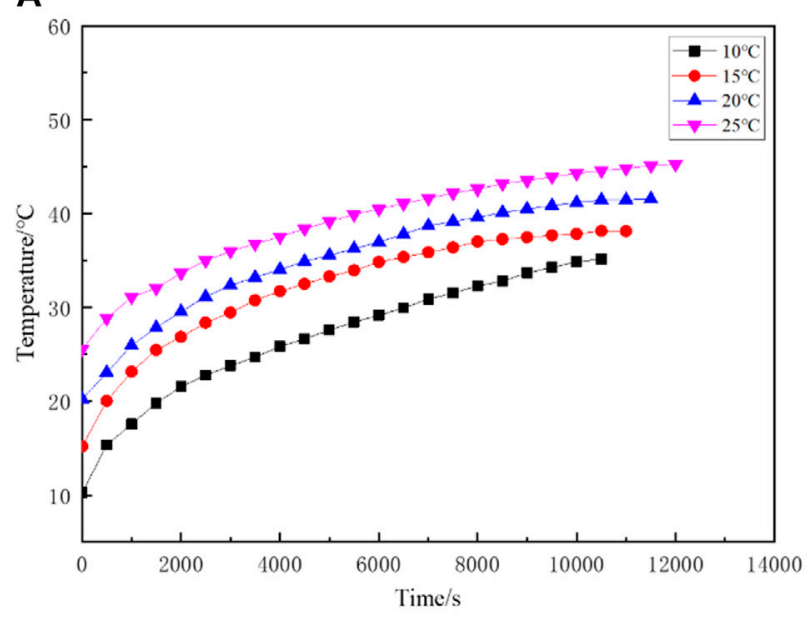

B

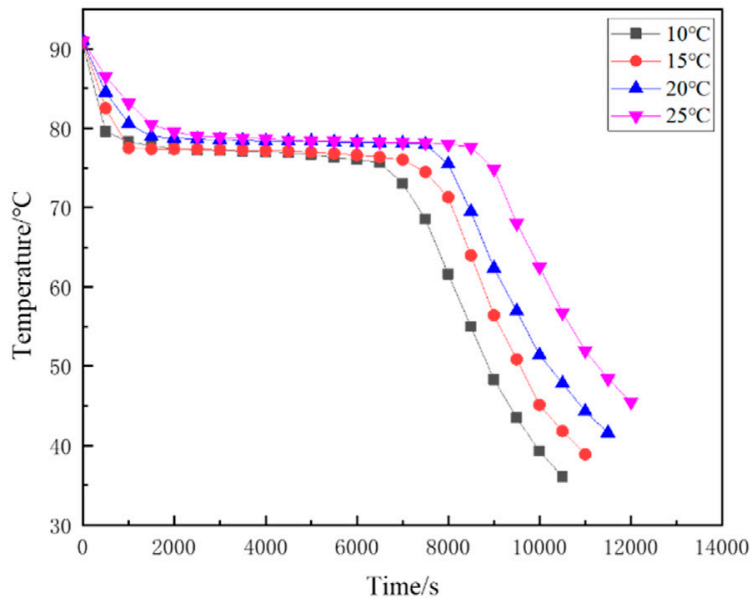

FIGURE 8 | The initial temperature of the cooling water changes at different times (A) Temperature rise of water tank (B) PCM temperature changes at measuring point 1.

TABLE 1 | Calculation of heat recovery rate when the initial temperature of cooling water is different

\begin{tabular}{|c|c|c|c|c|}
\hline $\begin{array}{l}\text { Initial temperature of } \\
\text { cooling water }\left({ }^{\circ} \mathrm{C}\right)\end{array}$ & $\begin{array}{c}\text { Maximum temperature of } \\
\text { cooling water }\left({ }^{\circ} \mathrm{C}\right)\end{array}$ & Heat storage (Q/kJ) & Recoverable heat $\left(Q_{w} / k J\right)$ & $\begin{array}{c}\text { Heat } \\
\text { recovery rate }(\%)\end{array}$ \\
\hline 10 & 35 & 1604.5 & 1050.0 & 65 \\
\hline 15 & 38 & 1588.7 & 966.0 & 61 \\
\hline 20 & 41 & 1572.9 & 882.0 & 56 \\
\hline 25 & 45 & 1551.8 & 840.0 & 54 \\
\hline
\end{tabular}

when the binary methanol-water solution is used as the filling medium with the filling ratio of 0.6 .

\section{Experimental Analysis of Heat Storage at Different Filling Medium}

As shown in Figure 8A represents the temperature rise of the water tank at different initial temperature of the cooling water, and Figure 8A depicts the temperature change of the PCM at the measurement point 1 with variable the initial temperature of the cooling water. In the exothermic process, when the initial cooling water temperature is set to $10^{\circ} \mathrm{C}$, the phase change latent heat release time of the PCM at measuring point 1 is about $5,000 \mathrm{~s}$; when the initial cooling water temperature is set to $15^{\circ} \mathrm{C}$, the PCM at measuring point 1 possesses the phase change latent heat release time of about $5,450 \mathrm{~s}$; when the initial cooling water temperature is set to $20^{\circ} \mathrm{C}$, the phase change latent heat release time of PCM at measuring point 1 is about $5,750 \mathrm{~s}$; when the initial cooling water temperature is set to $25^{\circ} \mathrm{C}$, the phase change latent heat release time of PCM at measurement point 1 is about $6,950 \mathrm{~s}$. According to the analysis of the experimental data, as the initial temperature of the cooling water increases, the phase change latent heat release time increases, and the total heat release time also increases. At the same time, it will cause a certain amount of heat loss. Therefore, the initial temperature of the cooling water can't be too high. The total required heat $Q$ absorbed by PCM is calculated as follows:

$$
\mathbf{Q}=\mathbf{Q}_{1}+\mathbf{Q}_{2}+\mathbf{Q}_{3}
$$

The heat recovery quantity $Q_{w}$ is the heat recovered from the heat accumulator in the water tank. The water flowing out of the water tank passes through the cooling water fluid channel of the heat accumulator and absorbs the heat when it is heated from the initial temperature to the final temperature. which is:

$$
\mathrm{Q}_{\mathrm{w}}=\mathrm{C}_{\mathrm{w}} \cdot \mathrm{M}_{\mathrm{w}} \cdot \Delta \mathrm{T}_{\mathrm{w}}=\mathrm{C}_{\mathrm{w}} \cdot \rho_{\mathrm{w}} \cdot \mathrm{V}_{\mathrm{w}} \cdot \Delta \mathrm{T}_{\mathrm{w}}
$$

Where, $C_{w}$ is the specific heat capacity of the cooling water, that is, $4.2 \mathrm{~kJ} /(\mathrm{kg} \cdot \mathrm{K}) ; M_{w}$ is the quality of the material; $\rho_{w}$ is the density of the cooling water, that is $1 \mathrm{~kg} / \mathrm{L} ; V_{w}$ is the volume of the cooling water, that is $10 \mathrm{~L} ; \Delta T_{w}$ is the initial and ending temperature of the cooling water difference. The heat recovery rate is $Q_{w}$ as a percentage of the total heat storage $Q$. According to the previous experiments, the maximum temperature of the cooling water at different initial temperatures of the cooling water is different, that is, the heat recovery rate is calculated as shown in the following Table 1:

Table 1 shows the calculation of the heat recovery rate during exothermic process at different initial cooling water temperature. The data demonstrates that the heat recovery rate is the highest 
when the initial cooling water temperature is $10^{\circ} \mathrm{C}$, and the heat recovery rate is the lowest when the initial cooling water temperature is $25^{\circ} \mathrm{C}$. Therefore, when the binary methanolwater solution is used as the filling medium, the heat recovery rate during the exothermic process decreases as the initial temperature of the cooling water increases. In practical applications, the appropriate initial temperature of the cooling water should be selected according to the needs to reduce heat loss.

\section{CONCLUSION}

In order to improve the heat storage and release performance of the PHP accumulator, the fluid flow model of PHP is firstly simulated and analysed. Additionally, the PHP and PCM are coupled in the experimental design. A novel binary methanolwater solution is prepared as the filling medium for experimental analysis. Concluded as follow:

1) In the heat storage process, the variation of temperature at each measurement point over time is investigated by varying the inlet flow rate and heating temperature of the heat source at different flow rates and heating temperatures. The results show that the larger the flow rate and the higher the heating temperature, the shortest time is spent in the phase change heat storage process. However, considering the safety and cost factors, the experimental heating flow rate is $0.6 \mathrm{~m}^{3} / \mathrm{h}$, and the heating temperature is $120^{\circ} \mathrm{C}$.

2) During the experiment, by changing the charging medium and charging rate in PHP, the time change at the measuring point 1 of the device was investigated. The results show that the use of binary methanol-water solution as the filling medium is more effective than the one-component filling medium, and the filling ratio of the PHP should not be too large, and the heat storage effect of the device is the best.

3) During the exothermic process, by changing the initial temperature of the cooling water, the influence of the initial temperature on the exothermic temperature of the device was researched. The results show that the lower the

\section{REFERENCES}

Akachi, H. (1993). Structure of Micro-heat Pipe. U.S.Patent 5,219,020.

Alhuyi Nazari, M., Ahmadi, M. H., Ghasempour, R., and Shafii, M. B. (2018). How to Improve the thermal Performance of Pulsating Heat Pipes: A Review on Working Fluid. Renew. Sust. Energ. Rev. 91 (March 2017), 630-638. doi:10. 1016/j.rser.2018.04.042

Bilal, A., Zubair, M., Memon, Z. A., Ghalleb, N., and Tlili, I. (2021). Comparative Analysis of Dish Stirling Engine and Photovoltaic Technologies : Energy and Economic Perspective. Sustainable Energ. Tech. Assessments 44 (August 2020), 101028. doi:10.1016/j.seta.2021.101028

Chen, X., Lin, Y., and Shao, S. (2019). Influences of Inclination Angle and Heating Power on Heat Transfer Performance of Ethane Pulsating Heat Pipe. CIESC J. 70 (04), 1383-1389. doi:10.1016/j.applthermaleng.2021.116847

Cui, X., Duan, W., Qiao, T., and Zhu, Y. (2014). Heat Transfer Performance of Pulsating Heat Pipe with Ethanol-Based Binary Mixtures. CIESC J. 65 (10), 2852-2860. doi:10.3969/j.issn.0438-1157.2014.10.015 initial temperature of cooling water, the higher the heat recovery rate.

\section{DATA AVAILABILITY STATEMENT}

The original contributions presented in the study are included in the article/Supplementary Material, further inquiries can be directed to the corresponding author.

\section{AUTHOR CONTRIBUTIONS}

$\mathrm{XhL}$ write the paper and implement the experiments. XL supervises the whole process. SC to help set up the device test bench. $\mathrm{CZ}$ is responsible for market research.

\section{AUTHOR CONTRIBUTIONS}

All authors listed have made a substantial, direct, and intellectual contribution to the work and approved it for publication.

\section{FUNDING}

The authors gratefully acknowledge the financial support provided by the Natural Science Foundation Project of Guangxi (2018GXNSFAA138157); High-level talent research start-up funding project (2017KYQD210); Provincial Science and Technology Department Science and Technology Plan Science and Technology base and Talent Special (GuikeAD18281082).

\section{ACKNOWLEDGMENTS}

College of Mechanical and Marine Engineering and Beibu Gulf University are greatly acknowledged for their financial support in making this research possible.

Czajkowski, C., Nowak, A. I., Błasiak, P., Ochman, A., and Pietrowicz, S. (2020). Experimental Study on a Large Scale Pulsating Heat Pipe Operating at High Heat Loads, Different Adiabatic Lengths and Various Filling Ratios of Acetone, Ethanol, and Water. Appl. Therm. Eng. 165, 1-15. doi:10.1016/j.applthermaleng.2019.114534

Dong, K.-Y., Sun, R.-J., Li, H., and Jiang, H.-D. (2017). A Review of China's Energy Consumption Structure and Outlook Based on a Long-Range Energy Alternatives Modeling Tool. Pet. Sci. 14 (1), 214-227. doi:10.1007/s12182016-0136-z

Gołaś, J., Zarębska, K., Nosek, K., Szramowiat-Sala, K., and Marczak, M. (2019). Energy and Environment as the Foundations for Sustainable Development. Environ. Sci. Pollut. Res. Int. 26 (9), 8359-8361. doi:10.1007/s11356-019-04299-8

Hoseinzadeh, S., and Stephan Heyns, P. (2020). Thermo-Structural Fatigue and Lifetime Analysis of a Heat Exchanger as a Feedwater Heater in Power Plant. Eng. Fail. Anal. 113, 104548. doi:10.1016/j.engfailanal.2020.104548

Hoseinzadeh, S., Ghasemiasl, R., Havaei, D., and Chamkha, A. J. (2018). Numerical Investigation of Rectangular Thermal Energy Storage Units with Multiple Phase Change Materials. J. Mol. Liquids 271, 655-660. doi:10.1016/j.molliq.2018. 08.128 
Hoseinzadeh, S., Sohani, A., Shahverdian, M. H., Shirkhani, A., and Heyns, S. (2021). Acquiring an Analytical Solution and Performing a Comparative Sensitivity Analysis for Flowing Maxwell Upper-Convected Fluid on a Horizontal Surface. Therm. Sci. Eng. Prog. 23 (October 2020), 100901. doi:10.1016/j.tsep.2021.100901

Kamil, M. (2021). Analysis of Thermal Creep Effects on Fluid Flow and Heat Transfer in a Microchannel Gas Heating. J. Therm. Sci. Eng. Appl. 13 (December), 1-12. doi:10.1115/1.4050236

Khan, S. U., Al-Khaled, K., Aldabesh, A., Awais, M., and Tlili, I. (2021). Bioconvection Flow in Accelerated Couple Stress Nanoparticles with Activation Energy : Bio - Fuel Applications. Scientific Rep. 11, 1-15. doi:10. 1038/s41598-021-82209-0

Khandekar, S., Dollinger, N., and Groll, M. (2003). Understanding Operational Regimes of Closed Loop Pulsating Heat Pipes: An Experimental Study. Appl. Therm. Eng. 23 (6), 707-719. doi:10.1016/ s1359-4311(02)00237-5

Konuklu, Y., Şahan, N., and Paksoy, H. (2018). 2.14 Latent Heat Storage Systems. Compr. Energ. Syst., 396-434. doi:10.1016/b978-0-12-809597-3.00231-5

Kumar, R., and Kumar, A. (2021). Optimal Scheduling of Variable Speed Pumped Storage, Solar and Wind Energy System. Energy Sourc. A: Recovery, Utilization, Environ. Effects, 1-16. doi:10.1080/15567036. 2021.1892243

Luo, X., Zhang, X., Hua, W., and Mao, F. (2017). Experimental Analysis on Heat Storage of Pulsating Heat Pipe Phase Change Heat Accumulator. Huagong Xuebao/CIESC J. 68 (7), 2722-2729. doi:10.11949/j.issn.0438-1157.20161297

Markal, B., and Varol, R. (2020). Thermal Investigation and Flow Pattern Analysis of a Closed-Loop Pulsating Heat Pipe with Binary Mixtures. J. Braz. Soc. Mech. Sci. Eng. 42 (10), 1-18. doi:10.1007/s40430-020-02618-6

Mikulčić, H., Wang, X., Duić, N., and Dewil, R. (2020). Environmental Problems Arising from the Sustainable Development of Energy, Water and Environment System. J. Environ. Manage. 259 (Apr.1), 109666.1-109666.6. doi:10.1016/j. jenvman.2019.109666

Nazari, M. A., Ghasempour, R., Ahmadi, M. H., Heydarian, G., and Shafii, M. B. (2018). Experimental Investigation of Graphene Oxide Nanofluid on Heat Transfer Enhancement of Pulsating Heat Pipe. Int. Commun. Heat Mass Transfer 91, 90-94. doi:10.1016/j.icheatmasstransfer.2017.12.006

Rudra Murthy, B. V., Nidhul, K., and Gumtapure, V. (2021). Performance Evaluation of Novel Tapered Shell and Tube Cascaded Latent Heat Thermal Energy Storage. Solar Energy 214, 377-392. doi:10.1016/j. solener.2020.11.069

Sheng, Q., Xing, Y., and Heng, L. (2014). Experiment on Thermal Storage Performance of Barium Hydroxide Octahydrate Phase Change Material. J. Beijing Univ. Aeronautics Astronautics 40 (5), 635-638. doi:10.13700/j.bh. 1001-5965.2013.0385
Sheng, Q., Xing, Y., and Wang, Z. (2013). Preparation and Performance Analysis of Metal Foam Composite Phase Change Material. CIESC J. 64 (10), 3565-3570. doi:10.3969/j.issn.0438-1157.2013.10.011

Shiina, Y. (2006). Reduction of Temperature Changes in Heat Transfer Fluid by the Use of Latent Heat Storage Technology. Trans. At. Energ. Soc. Jpn. 5 (3), 190-199. doi:10.3327/taesj2002.5.190

Škvorc, P., and Kozmar, H. (2021). Wind Energy Harnessing on Tall Buildings in Urban Environments. Renew. Sust. Energ. Rev. 152, 111662. doi:10.1016/j.rser. 2021.111662

Tieliang, Q., Cui, X., and Han, H. (2014). Research of the Heat-Transfer Performance on Methanol/Acetone Oscillating Heat Pipe. J. Mech. Eng. 50 (18), 148-154. doi:10.3901/JME.2014.18.148

Tlili, I., Samrat, S. P., and Sandeep, N. (2021). A Computational Frame Work on Magnetohydrodynamic Dissipative Flow over a Stretched Region with Cross Diffusion: Simultaneous Solutions. Alexandria Eng. J. 60 (3), 3143-3152. doi:10. 1016/j.aej.2021.01.052

Wan, R., and Ni, M. (2020). Sustainable Development of Energy, Water, and Environment Systems. Environ. Sci. Pollut. Res. Int. 27 (12), 12839-12841. doi:10.1007/s11356-020-08279-1

Wei, C., Löschel, A., and Managi, S. (2020). Recent Advances in Energy Demand Research in China. China Econ. Rev. 63, 101517. doi:10.1016/j.chieco.2020.101517

Wei, D. (2016). The Future of China's Energy, The Northeast Asian Econ. Rev., 4 (1), 3-10.

Zhu, Y., Cui, X., Han, H., and Sun, S. (2014). The Study on the Difference of the Start-Up and Heat-Transfer Performance of the Pulsating Heat Pipe with Water-acetone Mixtures. Int. J. Heat Mass Transfer 77, 834-842. doi:10.1016/j. ijheatmasstransfer.2014.05.042

Conflict of Interest: The authors declare that the research was conducted in the absence of any commercial or financial relationships that could be construed as a potential conflict of interest.

Publisher's Note: All claims expressed in this article are solely those of the authors and do not necessarily represent those of their affiliated organizations, or those of the publisher, the editors and the reviewers. Any product that may be evaluated in this article, or claim that may be made by its manufacturer, is not guaranteed or endorsed by the publisher.

Copyright (C) $2022 \mathrm{Lu}, \mathrm{Luo}$, Cao and Zou. This is an open-access article distributed under the terms of the Creative Commons Attribution License (CC BY). The use, distribution or reproduction in other forums is permitted, provided the original author(s) and the copyright owner(s) are credited and that the original publication in this journal is cited, in accordance with accepted academic practice. No use, distribution or reproduction is permitted which does not comply with these terms. 